\title{
Spatial study of causes and effects of the sandstorms using meteorological data and GIS: The case of Nasiriyah city, Iraq
}

\author{
Mohammad H. AL-Umar ${ }^{1}$, Murtadha S. Satchet ${ }^{2}$, Basim M. Al-Zaidi ${ }^{3}$, Alkhafaji R. Abood ${ }^{4}$ \\ ${ }^{1-4}$ Department of Civil Engineering, University of Thi Qar, Nasiriyah, Iraq
}

\begin{abstract}
The reoccurrence of sandstorms in Nasiriyah city (Southern Iraq) throughout the Summer season is a very important phenomenon and distinctive case that comes from the nearby regions. These storms restrict the financial activities of the city with expanded municipal effort as well as other well-being and environmental problems, and then bring a huge risk to the local residents. This paper uses Geographic Information System (GIS) and Remote Sensing Imagery to dimensionally discover the reasons causing sandstorms, understand the changes within certain periods of time, and then measure the sand-plume coverage during storms. This work has also made an attempt to get the correlation between meteorological records and spatial outputs to predict the direction and coverage range of the predicted future sandstorms which could help to take protective and preventive measures for the sake of the human being. The periods between 1972 and 2018 have been adopted to study the phenomena by using the information archive of the Nasiriyah Meteorological Center together with NASA's open-source climate data and Landsat satellite imagery.
\end{abstract}

\begin{tabular}{l}
\hline Keywords: $\quad$ Sandstorms, Spatial study, GIS, Nasiriyah city, Meteorological \\
\hline Corresponding Author: \\
Mohammad H. AL-Umar \\
Department of Civil Engineering, University of Thi Qar, Nasiriyah, Iraq \\
E-mail: mohammadhydar20@ yahoo.com \\
\hline \hline
\end{tabular}

\section{Introduction}

Sandstorms and duststorms are natural disaster phenomenon that occurs more frequently in dry and semi-dry areas. The reason for this phenomenon is the contact of numerous dependent factors that expand through several regional countries. The main causes of this storm are being longtime of inadequate and not effective farming methods. Problems connected with managing water assets and environmental condition changes especially the climatic changes still contribute to shriveled vegetation coverage, desertification, and drought, which definitely influences the rise of the regional dust-storm problem [1].

The effect of mineral dust aerosols in the Earth's system depends primarily on particle characteristics like size, mineralogy, and shape. But these characteristics can be changed in the course of dust transportation [2]. These characteristics are first recognized by the source regions they transport from. Thus, due to the high spatial diversity of the dust plume characteristics along with its transportation, remote sensing could be an associated methodology of finding and mapping of dust disasters [3,4] and has recently been utilized to verify the dust source zone with a distinct degree of success[5,7]. This phenomenon is a huge existing problem in Iraq mainly during the last decades [8]. These natural disasters are reasons for many problems 
because of their effects on human well-being, society and the environment as examples of the impacts of these natural phenomena on numerous fields of life, problems in air and land proceed, soil erosion, desertification, destruction of plants, agricultural infrastructure, etc. [9, 10].

Iraq is one of the countries geographically situated in a place that sand and sandstorms regularly hit and expands for several days [11]. Sandstorms and dust are two of the most significant natural challenges confrontation Iraqi areas which are placed in the dry and semi-dry areas. There is an important increase in the depth and the frequency of these natural disasters in the previous many years [8]. The Ministry of Environment in Iraq registered 283 dusty days and 122 dust storms, sources suggest that during the next decade, Iraq may face 300 dusty days and dust storms each year [12]. Sandstorms and dust are a stable problem in Iraq and different regions in the Middle East especially in the Spring and Summer months because the strong northwesterly winds acknowledged "shamal winds" [13].

In the summer season, the northerly winds "shamal winds" are the dominant winds that prevail over most of Iraq. The southern part of Iraq is more influenced by the southern and southern - easterly "Sharqi" winds, a dry, dusty wind with blasts speed of mean annual around eighty kilometers an hour. It starts in the Spring from April to early June and again occurs in Autumn from late September through November. This wind carries with it extreme sandstorms that can rise to heights of several thousand meters. During summer from the middle of June to the middle of September the Shamal wind blows from the north and northwest. The dry air gives escalated sun warming which can be the reason for dry soil and desertification. It is particularly these two winds, which produce extreme dry dust-storms in the region[11].

The wind has the ability to carry mineral aerosol (dust) and sand-grain material for long distances from the source areas of these materials[13]. That is the reason faraway sensing and Geographical Information System (GIS) technologies can find and mark on the map these events with the help of modern sensor skills and set up methods for research and monitoring [7, 13].

Different satellite information can be used to tune dust and sand-storm pathways which include Total Ozone Mapping Spectrometer (TOMS), Advanced Very-High-Resolution Radiometer (AVHRR), and of course Moderate Resolution Imaging Spectroradiometer (MODIS).

Geographical Information System (GIS) has a perfect solution for managing big spatial climate datasets of a numerous quantity of GIS applications. They become key management aspects in weather-processing structures giving chance for interpolation, monitoring, and animation, etc. of climate statistics throughout any degree of the atmosphere where GIS is used to make warnings to definite places using far off sensing skills [14]. The GIS provides a detailed quantitative sense of detecting the environmental phenomena for many life aspects where it can provide different types of outputs such as maps to analyze and describe the problems in the environment [15]. GIS technique has the function to take huge spatial patterns; they can analyze both the spatial and temporal fields' structural phenomena.

The track manager gives different techniques that can be used in monitoring many natural disasters like hurricanes, sand, and sandstorms, underground water studies, etc. [16]. In this study, our specific goal is to understand the impact of metrological parameters on the density and regularity of the dust and sandstorm disasters in Nasiriyah city and the impact of these storms on turning the areas into dry like desert and decreasing runoff in the study area by finding out the statistical researches between them and metrological parameters like temperature, rain, and runoff amount. Moreover, the feeding areas of these storms have been identified and mapped to point out how they blow into the study area by studying and analyzing the pathway of the winds in the region. A storm is a real of these phenomena using GIS particle tracking analysis where the direction of the storm, its altering size and the period of the occurrence are identified. 


\subsection{Study area}

The study area is Nasiriyah city, the center of Thi Qar Governorate, which is one of the largest cities in the south of Iraq. The estimated population of the city in 2019 about 580000 capita. The study area is located on the floodplain of Euphrates River, and it lies about $370 \mathrm{~km}$ southeast of Baghdad city. Figure 1 presents the study area, where we reported the locations of the main borders with the surrounding cities. It shares interior borders with Alshatrah district from the North and marshland area from the East and with the governorates of Basrah in the South and Muthanna from the West. It is located at 31.06 latitudes and 46.26 longitudes, and it is placed at an elevation 4-6 meters above sea level.

The climate of the Thi-Qar city is very dry which is normal for the region. The summer is always hot and dry; the common high temperature goes up above $50^{\circ} \mathrm{C}$ while the winter is mild. Rains are restricted to the months of November-April and average about $100 \mathrm{~mm}$ annually. Recently, climate changes affect badly on all parts of the province with the developing problems of dust and sandstorms that sweep the province, making economic, environmental and psychological damage. The motivation for choosing this city is the repetition of sandstorms during the year.

The area which is the primary source of these storms placed in the western boundaries of Thi- Qar province and reaches boundaries of $\mathrm{Al}$ Muthanna province in the West and Al-Qadisiyyah province in the North. It is geographically extended restricted between longitudes $45010^{\prime} \mathrm{E}, 46^{\circ} 00^{\prime} \mathrm{E}$ and latitudes $31^{\circ} 10^{\prime} \mathrm{N}, 32^{\circ} 00^{\prime} \mathrm{N}$. Figure 2 shows a sandstorm hitting Nasiriyah city that comes from the western bourders during August 2018. This kind of sandstorm has led to being hazard driving along thousands of kilometers on the highway in the study area due to invisible vision and dune layer over the road and then causing enormous traffic.

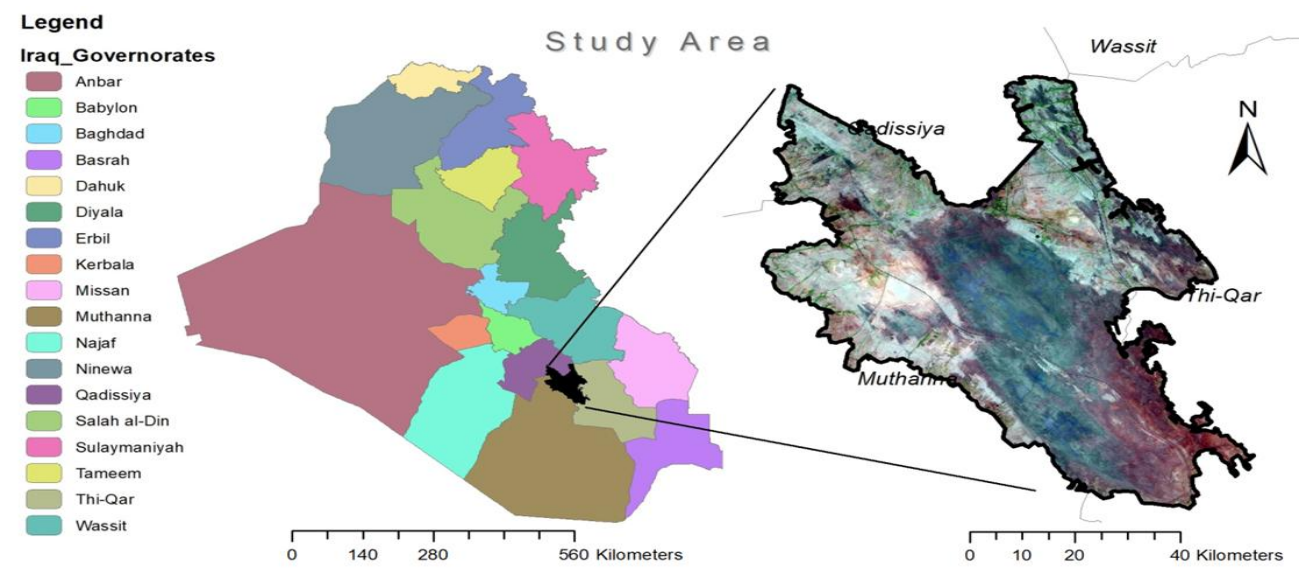

Figure 1. Map showing the location of the study area

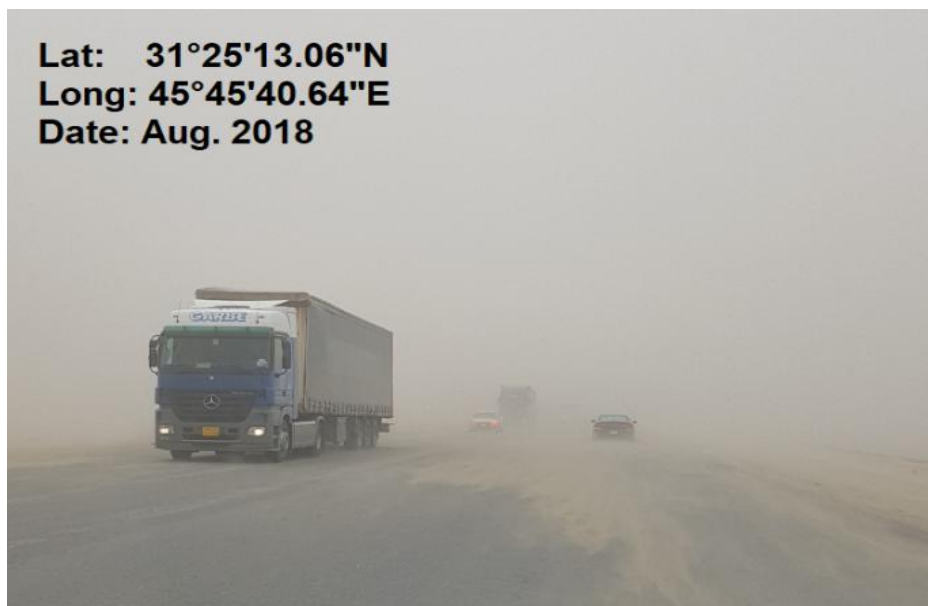

Figure 2. A sandstorm hitting nasiriyah city in august 2018, showing how dunes creeping over the highway western bourders of the study area (the image was taken by the author) 


\section{Dataset and methodology}

Different information sources have been used to study the occurring and frequent sandstorms in the study area, which can be classified as:

\section{Data Collection}

The current study includes a series of topographic maps for the Thi-Qar governorate and city map from relevant researchers. The required satellite imagery for the study area for the years of 1972, 1983, 1990, 2001, 2009 and 2018 was downloaded from the USGS Earth Explorer Landsat-7, 8 as shown in Figure 3. Satellite images of sandstorms each day from 2000 to 2017 were captured by Worldview satellites operated by the National Aeronautics and Space Administration (NASA). The satellite images were intended for the months particularly May, June, July, August, and September when the sandstorms were frequent and happened more often during these months.

The daily meteorological information review since 1981 was gathered from the Power Information Access Viewer operated by the National Aeronautics and Space Administration (NASA). The meteorological data reports were used for the period between 1940 and 2019 of the Nasiriyah station $\left(31^{\circ} 01^{\prime} 37^{\prime \prime} \mathrm{N}, 46^{\circ} 14^{\prime} 35^{\prime \prime} \mathrm{E}\right)$. This data involves the annual amount of rainfall, temperature, wind speed, and storm frequency.
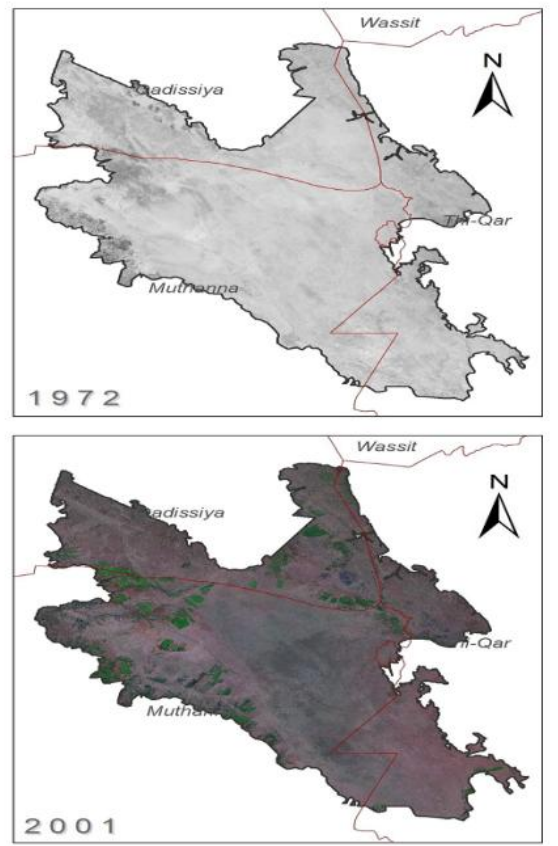

Legend
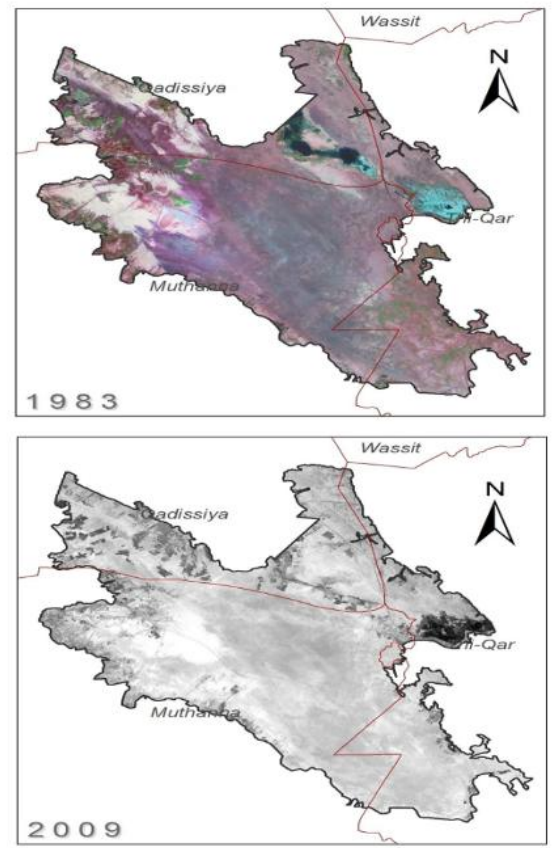

1983, 2001, 2018: Multispectral images 1972, 1990, 2009: Panchromatic images
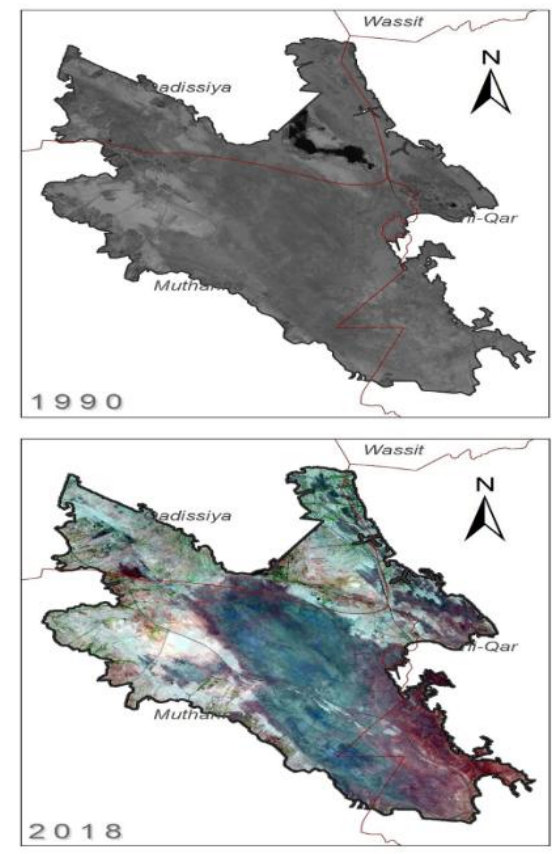

SCALE $1: 1,000,000$

Figure 3. An archive of satellite images Landsat-7, 8 to study the changes in the land cover of the study area during different years

\section{Geodatabase and Classification}

ArcGIS 10.5 was used to make a geographic information database for the study area and to collect a large number of satellite images after the engineering corrections process. The classification of satellite images by Landsat (using the Supervise Classification method) was carried out to studying the nature of the landcover of the study area for various years over the study period of $46 \mathrm{yr}$. The impact of sandstorms and their frequency, the coverage area and the cities that were ruined were studied with the help of the satellite images obtained by Worldview as shown in Figure 4. 


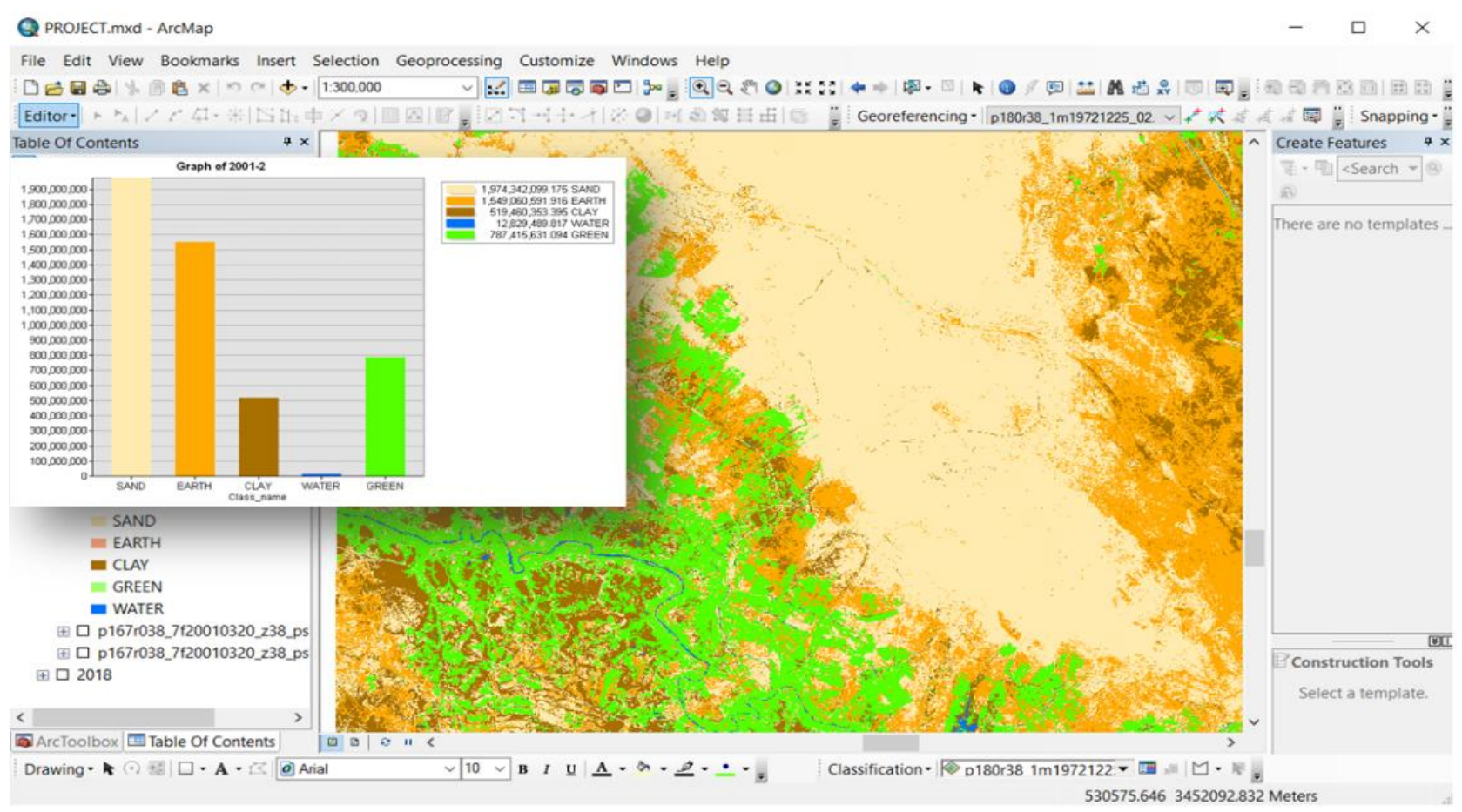

Figure 4. The nature of the landcover of the study area

\section{Meteorological information Management}

Dataset is collected and analyzed in different time periods which are daily, monthly, and annual. In particular, the data of meteorological elements was studied yearly, data obtained from Nasiriyah station was recorded monthly, while the data from the Power Data Access Viewer operated by NASA is archived daily.

In order to unify the time periods, the repetition of sandstorms during one year was estimated based on five months of the storm's activity (May, June, July, August, and September). However, the annual rainfall was calculated by taking the rest seven months into consideration.

After identifying the information of sandstorms occurrence in the study area from the observations of satellite images of WORLDVIEW satellite, data related to speed and wind direction which measured at 10 meters above earth surface were obtained from the POWER Data Access Viewer were linked with the length and the predetermined coverage area of sand storm in order to analyze the behavior of the sandstorm, as well as to predict the areas where the storms could be covered in future.

\section{Results and discussion}

\section{Results of the spatial determination of the area causing storms}

The geographical database made for this study points out that the area of causing a sandstorm is situated north-west Nasiriyah city with a total area of $2833 \mathrm{~km}^{2}$ which can be considered as dry and sandy. This area is linked with the administrative boundaries of three governorates (Muthanna, Thi-Qar, and Qadisiyah) with the level of the area indicated in Figure 5. On the other hand, the results of landcover showed changes in this area in the coming elected years. Moreover, this area neither expands on its Sandy nature nor greatly changes in terms of soil cover except rising in vegetation cover during the winter months as compared with the Summer months, Figure 6. 

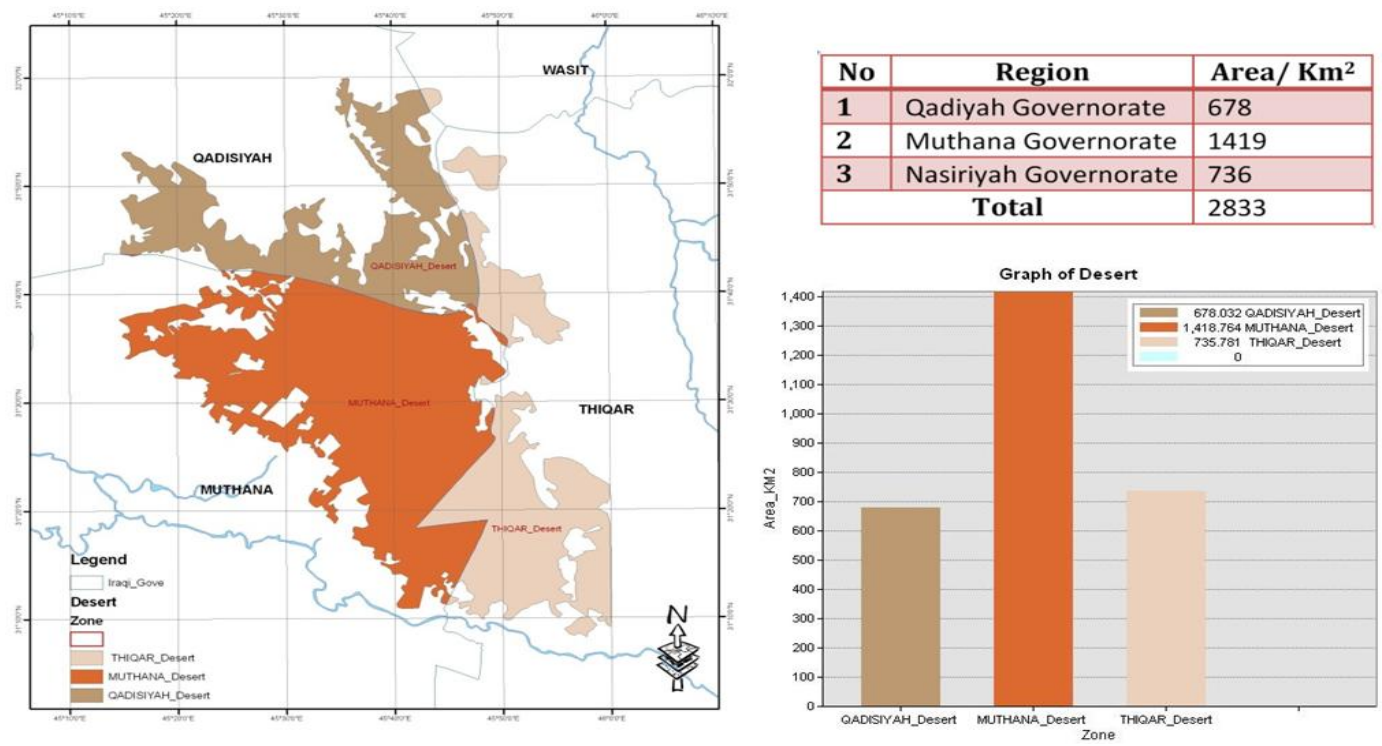

Figure 5. The Spatial determination of the area causing storms
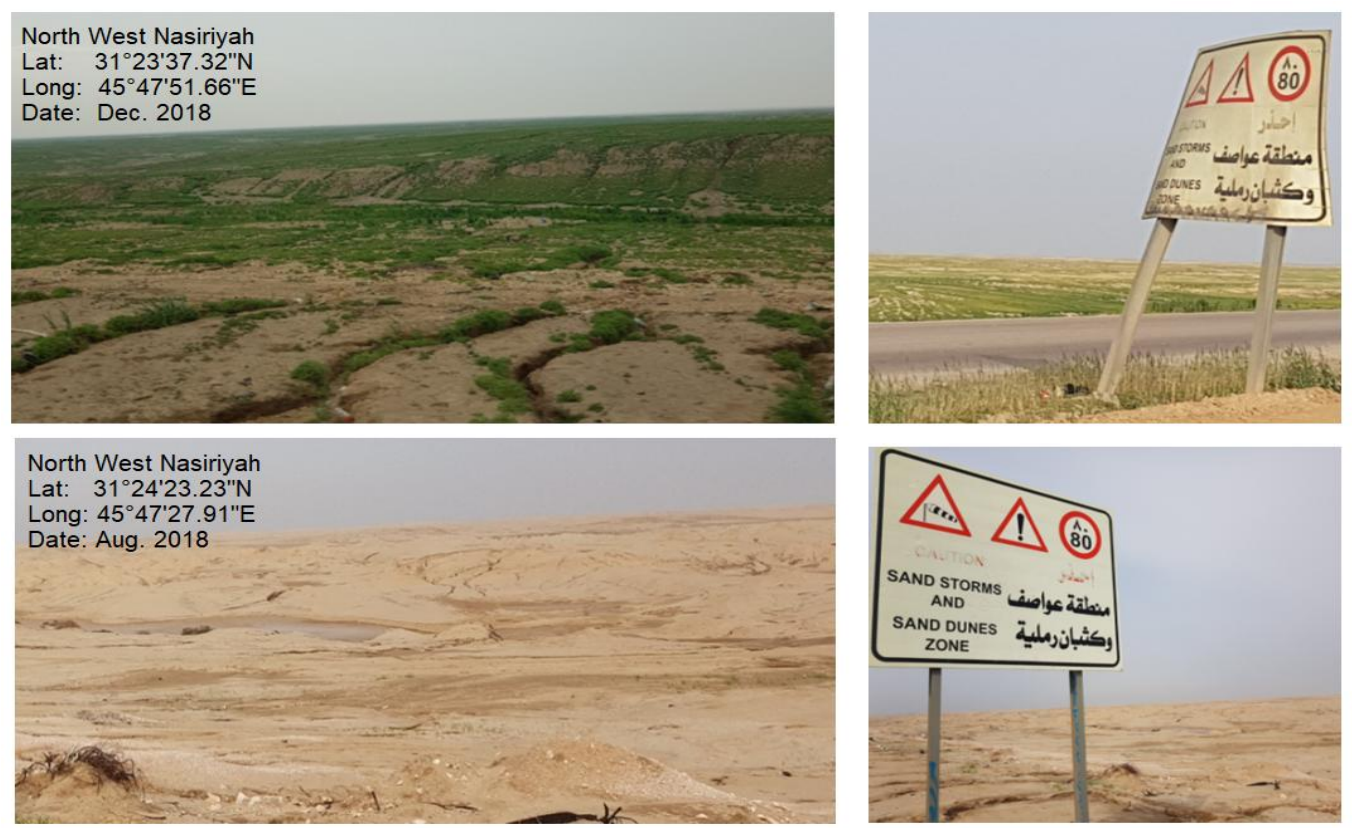

Figure 6. Variation in vegetation between the months of winter and summer

\subsection{Determination of the coverage of sandstorms}

By researching the extent and coverage of sandstorms taking into consideration the geographic database of the research and by the satellite images of Worldview, we can come to the following conclusions:

1. The impact of sandstorms formed from the sandy area situated in the north-west of Nasiriyah city cover hundreds of kilometers $(100-400 \mathrm{~km})$;

2. The lowest level of sandstorms estimated in the study area was $\sim 130 \mathrm{~km}$, and the maximum extent of the storm was $400 \mathrm{~km}$;

3. The lowest point covered by sandstorms was $\sim 3000 \mathrm{~km}^{2}$, and the largest coverage area was $\sim 12000 \mathrm{~km}^{2}$ when the extent of the storm exceeded $\sim 350 \mathrm{~km}$;

4. There is a direct connection between the depth and the coverage of the sandstorms as shown in Figure 7; 
5. The two most important aspects influencing the coverage of the sandstorms to Nasiriyah city or the nearby cities are the path of the storm and its distance extent; they depend on the speed and direction of the wind as shown in Figure 8;

6. The cities that are often damaged by these storms are: Batha, Nasiriyah, Suq al-Shuyukh, Karma Bani Saeed, and Al-Tar; and

7. At the maximum power of the storm (greater than $350 \mathrm{~km}$ ), the effect reaches the capital of the Kuwait State in the South of Iraq.

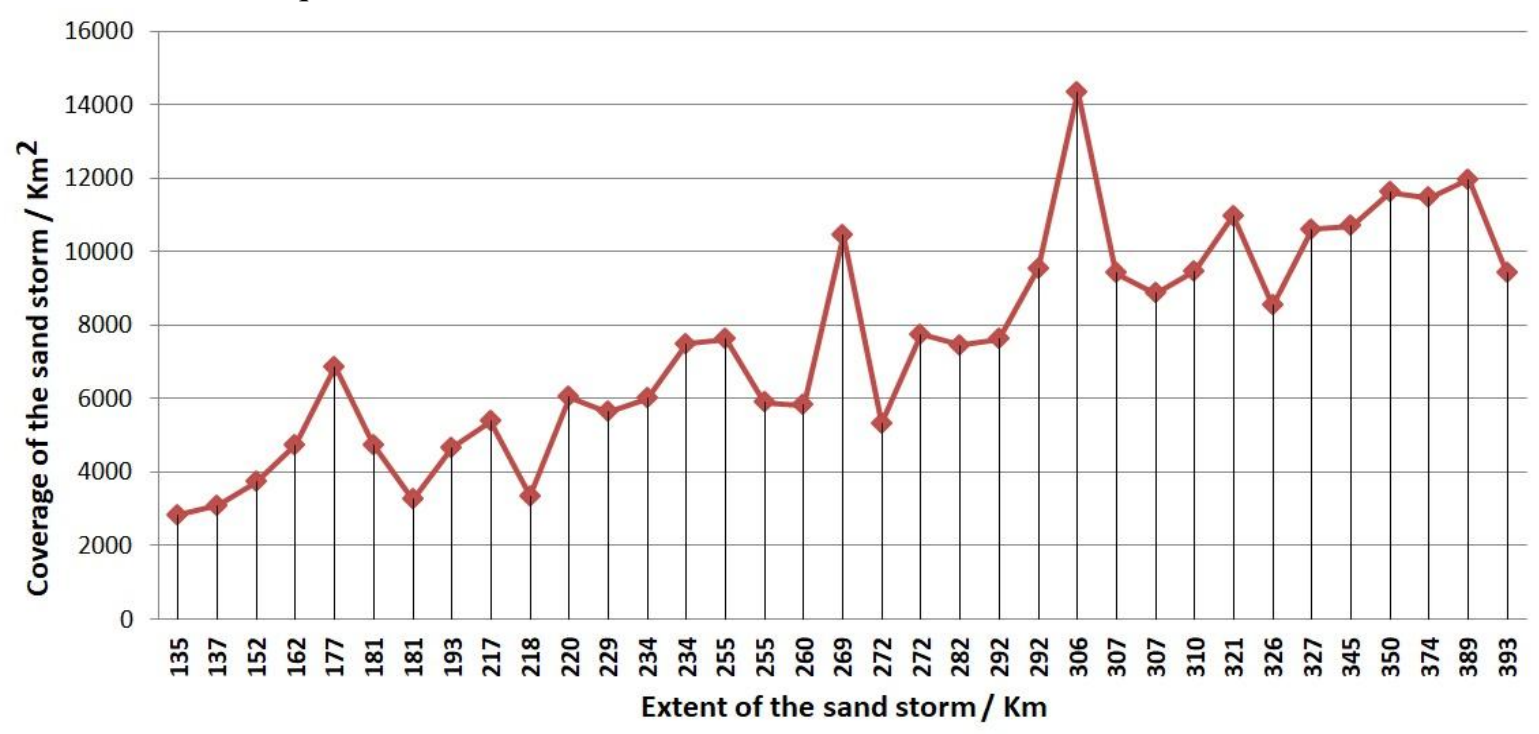

Figure 7. Relationship between the extent and coverage of the sandstorm
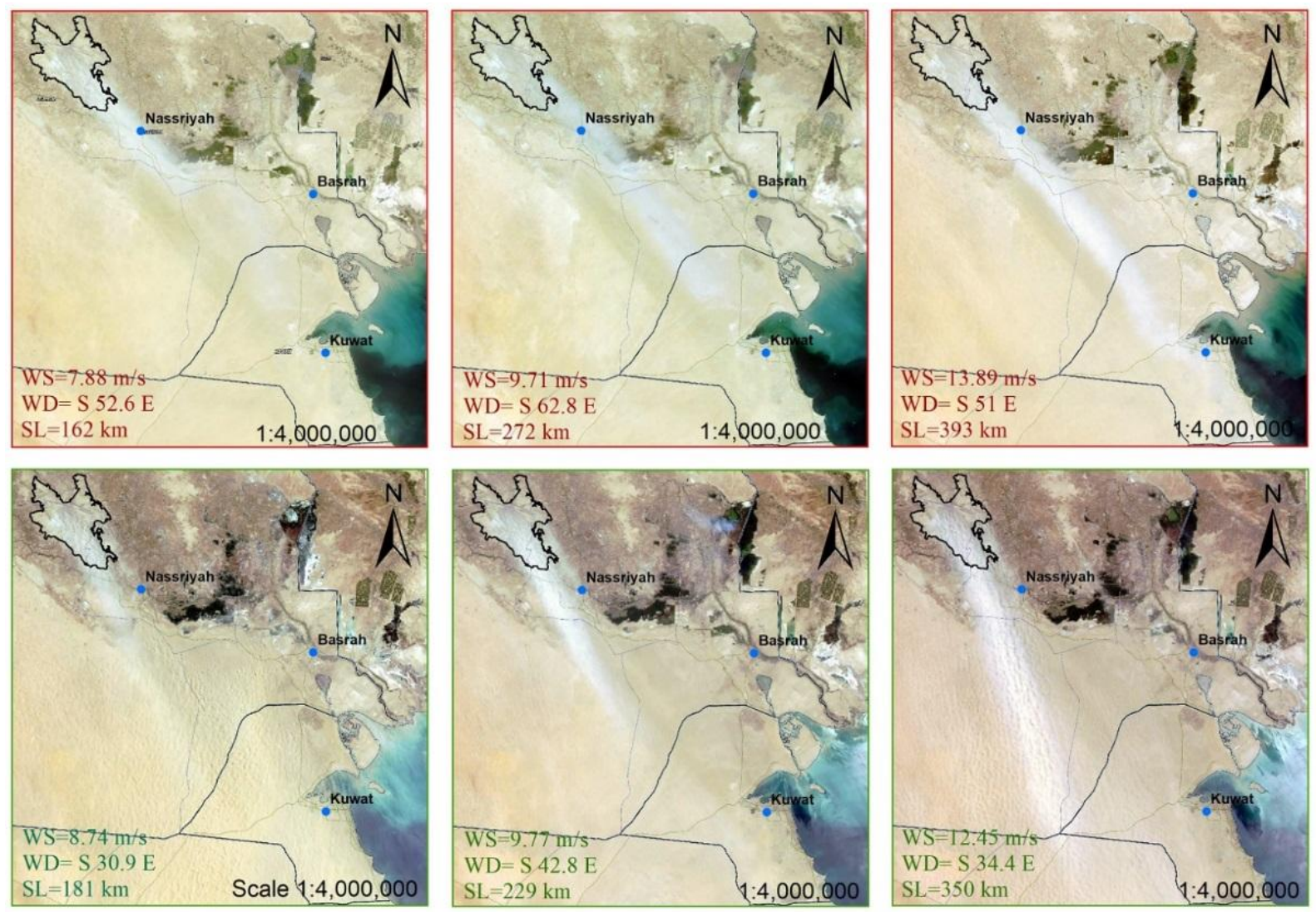

WS: Wind Speed , WD: Wind Direction , SL:Storm Length

Nasiriyah within the storm

Nasiriyah outside the storm

Figure 8. Effect of wind direction and velocity in the range and direction of the duststorms 


\subsection{The connection between the frequency of sandstorms and rainfall}

Comparing the amount of annual rainfall of the Nasiriyah meteorological station and the frequency of sandstorms according to the Worldview satellite facts, there was a clear relationship between the frequency of sandstorms and the level of rainfall in the same year. The relation coefficient between them is -0.511 , as explained in Figure 9.
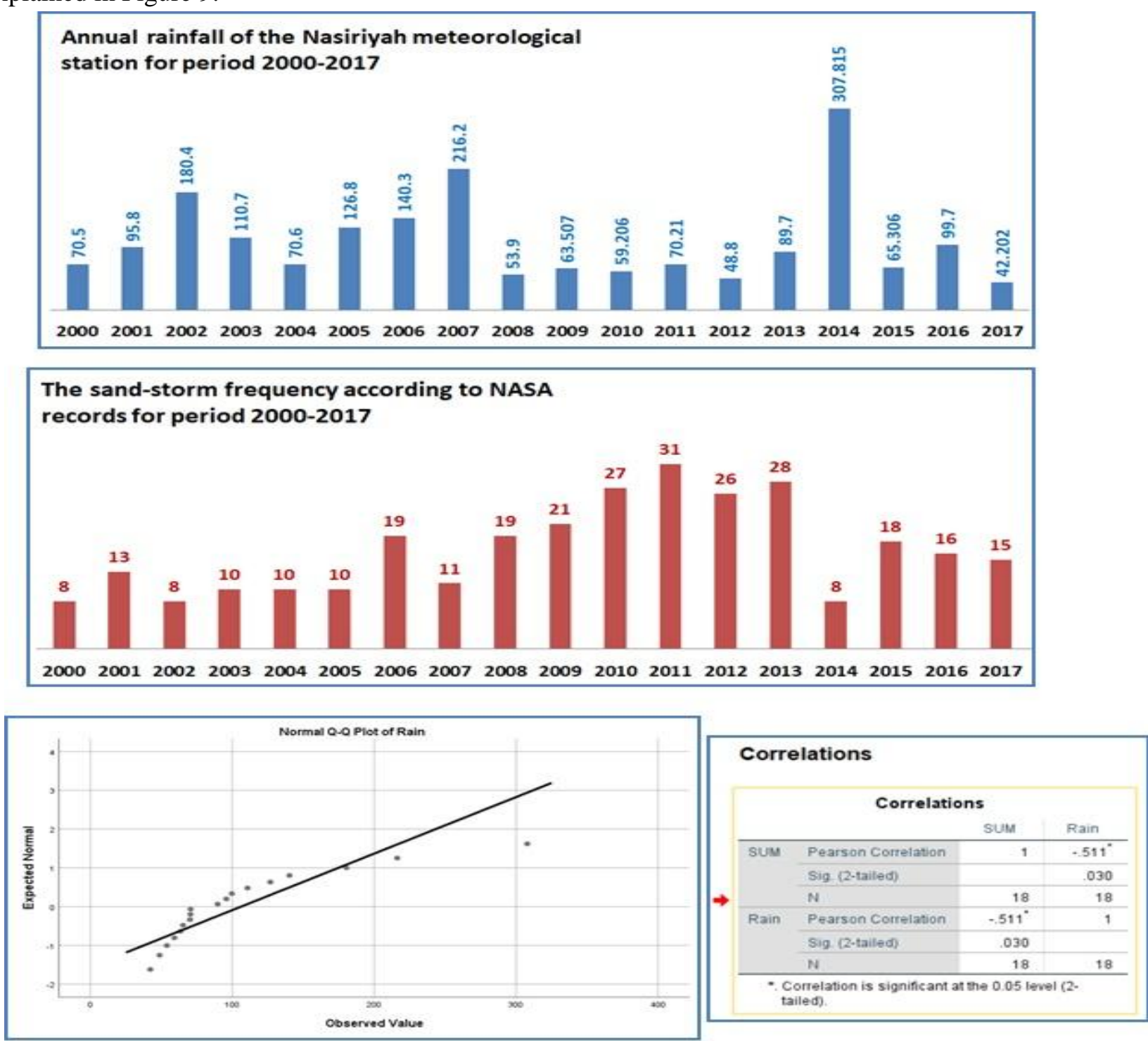

Figure 9. The relationship between the frequency of sandstorms and the amount of rainfall

\subsection{Connection the metrological data with the spatial output}

By connecting the spatial consequences of the sandstorm (extend and coverage area) based on the above results with the metrological information for the same storm day acquired from the POWER Data Access Viewer, the following results can be received:

1) Sandstorms occurred in Worldview satellites when the wind speed was $(6 \mathrm{~m} / \mathrm{s})$ or more;

2) There is a primary connection between wind speed and storm extent (Figure 10);

3) Wind direction is a necessary factor in the possibility of covering the sandstorm of Nasiriyah city or not;

4) Nasiriyah city lies within the sandstorm coverage if the full circular direction of the Azimuth winds between (115 - 135) degrees (Figure 11). 


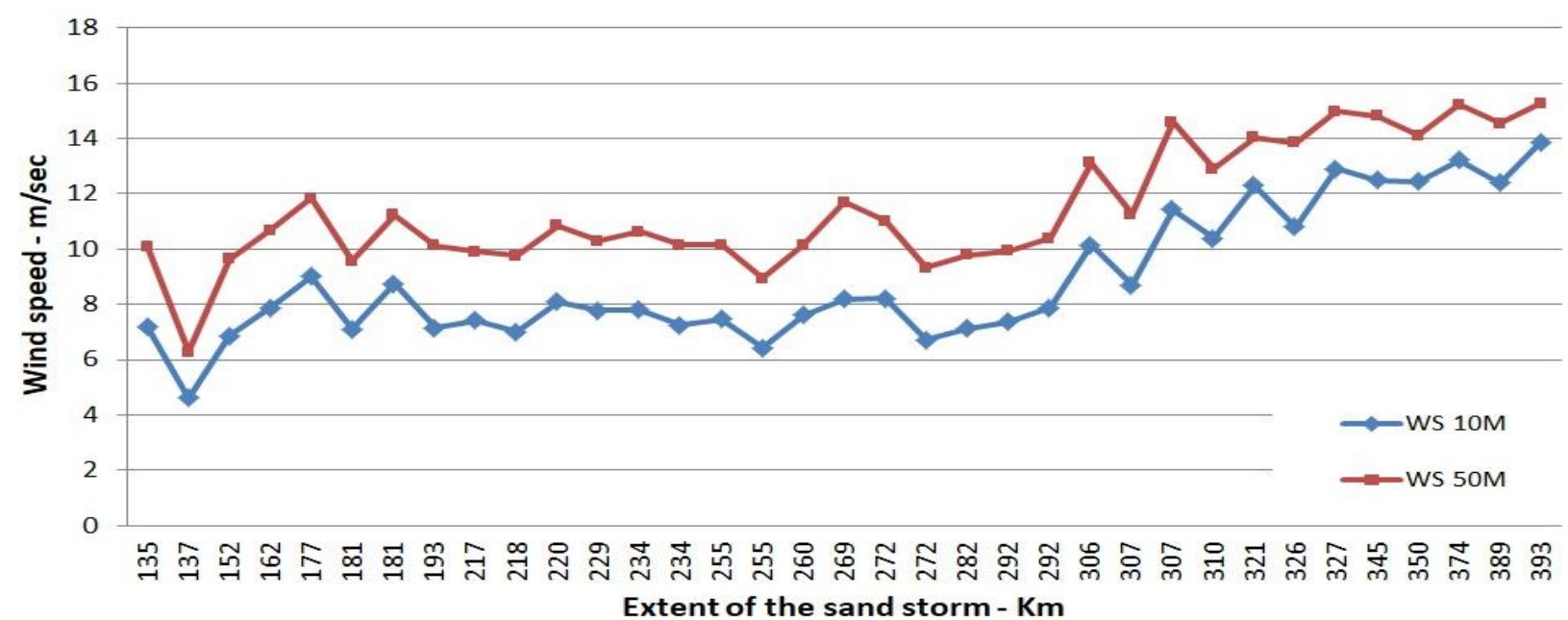

Figure 10. The relationship between wind speed and storm coverage

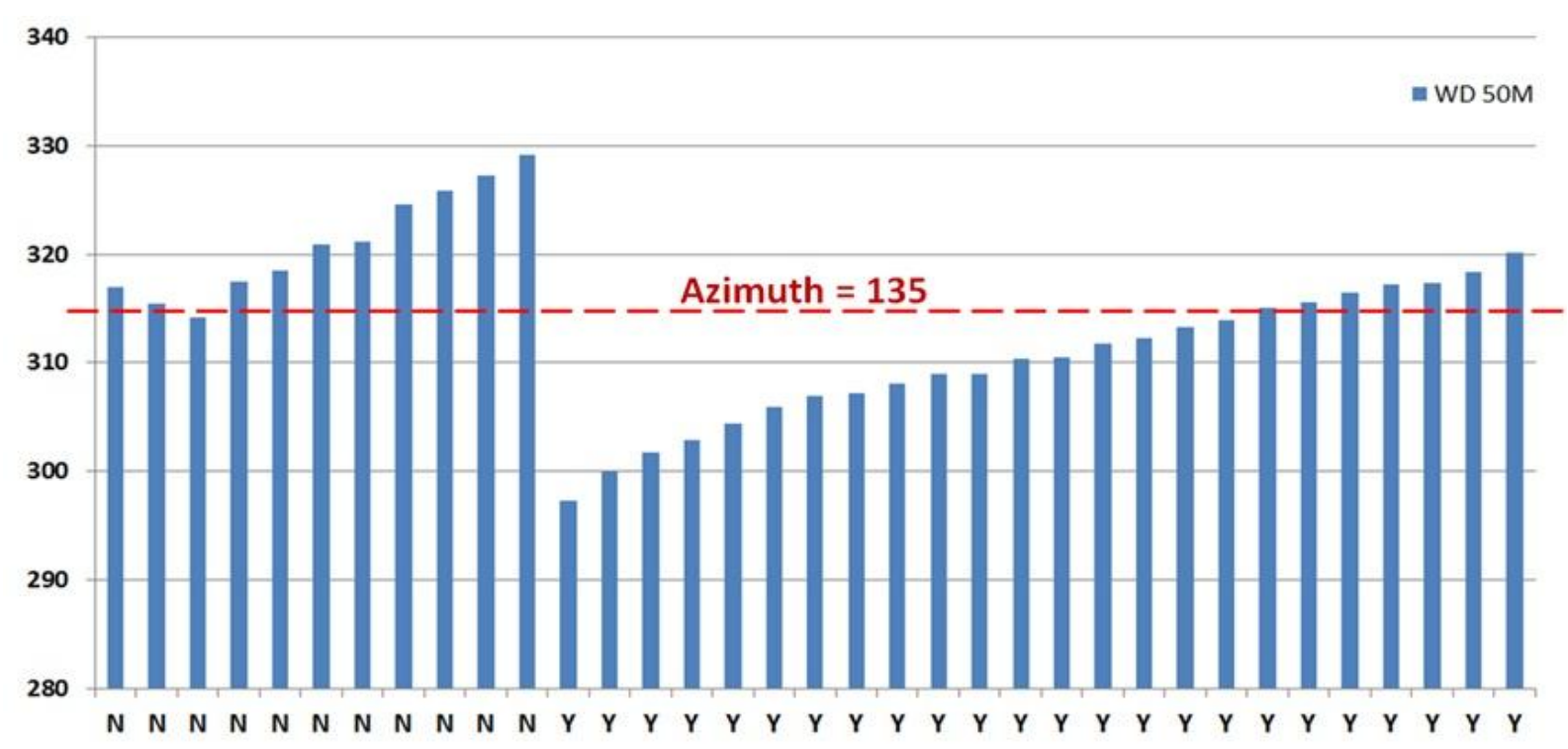

Figure 11. The role of wind direction in the possibility of covering the sandstorm of Nasiriyah city

\section{Conclusions}

The more important conclusions reached in this study are as follows:

1. Sandstorms in the study area occur at a wind speed of $(6 \mathrm{~m} / \mathrm{s})$ or more;

2. Nasiriyah city is covered by the sandstorm when the full circular direction of the wind is between (135-115) degrees;

3. The lowest extent of sandstorms was determined in the study area of $130 \mathrm{~km}$ at a wind speed of $(7 \mathrm{~m} / \mathrm{s})$, and the maximum extent of the storm was $400 \mathrm{~km}$ at wind speed $(13.8 \mathrm{~m} / \mathrm{s})$; and

4. The lowest region covered by sandstorms reached 3000 square kilometers, whilst the largest coverage was 12000 square kilometers at the ranges that exceeded $350 \mathrm{~km}$.

\subsection{Recommendations}

The following future investigations and works are recommended:

1. A new meteorological station can be set up inside the Nasiriyah oil field with the aid of Thi-Qar Oil

Company, this proposed station has to be situated in the center of the sand storming region, in order to 
check the meteorological information in a more accurate way. The location of the Nasiriyah air station is affected by the urban encroachment of Nasiriyah, and then to get on precise information; and

2. Working on the formation of joint task forces of the relevant governmental bodies (Thi-Qar Agriculture Directorate, Thi-Qar Irrigation Directorate, Thi-Qar Environment Directorate, Thi-Qar Oil Company, University of Thi-Qar, and others) in order to unite efforts and use modern methods and skills in limiting the phenomenon of increasing sandstorms in the study area.

\section{References}

[1] UN. Sand and Dust Storms Fact Sheet produced by joint analysis and policy unit (JAPU). Available at https://reliefwebint 2013.

[2] D. S. Mackie, P. W. Boyd, G. H. McTainsh, N. W. Tindale, T. K. Westberry, K. A. Hunter. Biogeochemistry of iron in Australian dust: From eolian uplift to marine uptake. Geochemistry, Geophysics, Geosystems; 9,2008.

[3] K. Badarinath, S. K. Kharol, V. Krishna Prasad, D. Kaskaoutis, H. Kambezidis. Variation in aerosol properties over Hyderabad, India during intense cyclonic conditions. International Journal of Remote Sensing; 29:4575, 2008.

[4] D. Kaskaoutis, H. Kambezidis, P. Nastos, P. Kosmopoulos. Study on an intense dust storm over Greece. Atmospheric Environment; 42:6884, 2008.

[5] J. Bullard, M. Baddock, G. McTainsh, J. Leys. Sub-basin scale dust source geomorphology detected using MODIS. Geophysical Research Letters ;35, 2008.

[6] N. Karimi, A. Moridnejad, S. Golian, J. M. Vali Samani, D. Karimi, S. Javadi. Comparison of dust source identification techniques over land in the Middle East region using MODIS data. Canadian Journal of Remote Sensing; 38:586,2012.

[7] M. C. Baddock, J. E. Bullard, R. G. Bryant. Dust source identification using MODIS: a comparison of techniques applied to the Lake Eyre Basin, Australia. Remote Sensing of Environment; 113:1511,2009.

[8] B. M. Yahya, D. Z. Seker. The Impact of Dust and Sandstorms in Increasing Drought Areas in Nineveh Province, North-western Iraq. Journal of Asian and African Studies;0021909618812913, 2018.

[9] H. E. Redmond, K. D. Dial. Thompson JE. Light scattering and absorption by wind blown dust: Theory, measurement, and recent data. Aeolian Research; 2:5, 2015.

[10] R. Washington, M. Todd, N. J. Middleton, A. S. Goudie. Dust-storm source areas determined by the total ozone monitoring spectrometer and surface observations. Annals of the Association of American Geographers; 93:297, 2003.

[11] V. Sissakian, N. Al-Ansari, S. Knutsson. Sand and dust storm events in Iraq. Journal of Natural Science; 5:1084,2013.

[12] M. Kobler. Dust storms of Iraq, UN Secretary General for Iraq, A ministerial meeting in Nairobi, Kenya. 2013.

[13] K. Badarinath, S. K. Kharol, D. Kaskaoutis, A. R. Sharma, V. Ramaswamy, H. Kambezidis. Long-range transport of dust aerosols over the Arabian Sea and Indian region-A case study using satellite data and ground-based measurements. Global and Planetary Change; 72:164,2010.

[14] H. Feidas, T. Kontos, N. Soulakellis, K. Lagouvardos. A GIS tool for the evaluation of the precipitation forecasts of a numerical weather prediction model using satellite data. Computers \& geosciences; 33:989,2007.

[15] K. Fedra. Urban environmental management: monitoring, GIS, and modeling. Computers, environment and urban systems ;23:443, 1999.

[16] T. C. Vance, S. Mesick, S. Cross. Integrating particle tracking models into a GIS for analysis and display of environmental phenomena. Proceedings of the 17th ACM SIGSPATIAL international conference on advances in geographic information systems: ACM; p. 460, 2009. 